\title{
EL RETRATO DE FRANCO, EL DE JOSÉ ANTONIO Y EL CRUCIFIJO. CONSTRUCCIÓN DE LA IDENTIDAD NACIONAL EN LOS ESCOLARES DE POSGUERRA
}

\author{
The Portraits of Franco, José Antonio and the Crucifix. \\ Construction of National Identity in Post-War Schoolchildren
}

\author{
Miriam Sonlleva Velasco \\ miriam.sonlleva@uva.es \\ Universidad de Valladolid. España \\ Carlos Sanz Simón \\ csa02@ucm.es \\ Universidad Complutense de Madrid. España \\ Luis Torrego Egido \\ Itorrego@pdg.uva.es \\ Universidad de Valladolid. España \\ Fecha de recepción: 31/08/2017 \\ Fecha de aceptación: 30/01/2018
}

\begin{abstract}
Resumen: La memoria de los escolares de posguerra guarda el recuerdo de una infancia marcada por la huella del nacionalcatolicismo. La estrecha vinculación entre la Iglesia y el Estado, tras el fin de las hostilidades, sentó los cimientos para la construcción de la identidad nacional en los estudiantes. En el artículo que presentamos, analizamos la narración de las vivencias infantiles del grupo de población nacido durante la guerra, para recomponer cómo fue transmitido ese ideario, a través de la interacción entre el estudiante y su contexto más próximo. A partir de la metodología biográfico-narrativa, -centrada en cuatro relatos de vida realizados a dos hombres y dos mujeres de clases populares, cuya infancia se enmarca en los años cuarenta- profundizamos en la consolidación del ideario político, religioso y moral franquista, a través de las enseñanzas que los niños y las niñas recibían en la escuela y se potenciaban a partir de otros conocimientos no formales, aprendidos desde las relaciones familiares y sociales. Constatamos que el uso de las fuentes orales desvela la conformación de elementos muy relevantes de la construcción de la identidad nacional, en especial los más propiamente subjetivos, como los procesos de naturalización de la discriminación,
\end{abstract}


la asunción de la arbitrariedad del poder o el valor de las rutinas, los símbolos y las celebraciones religiosas o patrióticas.

Palabras clave: identidad nacional; educación; dictadura; historia oral.

\begin{abstract}
The memory of the post-war schoolchildren keeps the memory of a childhood marked by the imprint of national-catholicism. The close link between Church and State after the end of hostilities laid the foundation for the construction of national identity in students. In this article that we present, the narrative of children's experiences of the population group born during the war, allows us to recompose how this idea was transmitted through the interaction between the student and his closest context. Through the biographical - narrative methodology, centered on four life stories made up of two men and two women from the popular classes whose childhood was framed in the 1940s, we deepened the consolidation of Franco's political, religious and moral ideology through teachings that boys and girls received in school and were strengthened from other non-formal learning, learned from family and social relationships. We found that the use of oral sources reveals the formation of very relevant elements of the construction of national identity, especially the most properly subjective ones, such as the naturalization processes of discrimination, the assumption of arbitrariness of power or value of routines, symbols and religious or patriotic celebrations.
\end{abstract}

Keywords: national identity; education; dictatorship; oral history.

SUMARIO: 1. Identidad nacional en la posguerra. 2. Identidad nacional en los años cuarenta y cincuenta. Hacia un estado de la cuestión. 3. Consideraciones metodológicas. 4. Escuela y sociedad en la posguerra. La identidad nacional a través de fuentes orales. 4.1. Aprender la identidad nacional en la escuela... 4.2. Identidad nacional y aprendizaje social desde la mirada infantil. 5. Consideraciones finales. 6 . Referencias bibliográficas.

La infancia debería ser la etapa más feliz en la vida del ser humano. En los países que gozan de estabilidad económica y política, los niños son cuidados, porque en ellos se deposita la esperanza de ver materializado el éxito y el bienestar social de la nación. Esta situación se revierte en tiempos de guerra, donde la población infantil se convierte en el grupo social menos protegido y más vulnerable. Precisamente, esta fragilidad es la que permite hacer más visibles las heridas físicas y psicológicas que dejan este tipo de conflictos armados (Yela, 2013).

La situación que vivieron los niños a lo largo de la Guerra Civil española y las consecuencias que tuvo este conflicto para la infancia han sido ya objeto de estudio en algunas investigaciones como las de Alted (1996, 1999 y 2003), Hernández, Sánchez y Pérez (2009), Gil y García (2009) o Lapeyre (2010).

Estas publicaciones revelan que la memoria de todas aquellas personas que vivieron su infancia bajo el telón de las hostilidades es algo más que un mero depósito de saberes. Se trata de una memoria «escondida en el cuarto de atrás de la conciencia», donde se refugia y espera paciente a que algún historiador la despierte de su letargo (Colmeiro, 2005, p. 30). Escribe Alted (2003), que ser niña o niño de la guerra no solo significa haber vivido la niñez en un país en guerra, sino que ese fenómeno condicionará toda su experiencia vital, algo que no se hubiera producido en otras circunstancias. Por ello, en la memoria de esta infancia navegan los temores, los deseos, los rechazos y las esperanzas de toda una colectividad (Peñamarín, 
2002). Escuchar sus relatos nos permite recorrer los lugares, los símbolos, las instituciones y los sentimientos invisibles desde los testimonios oficiales.

El estudio que presentamos tiene como objetivo investigar cómo fue transmitida la identidad nacional a los niños y niñas españoles durante la posguerra. Nos serviremos de cuatro relatos de vida -enmarcados en las décadas de 1940 y $1950-$, para analizar cómo las escuelas y la sociedad se convirtieron en los principales referentes para la construcción de esta identidad. Comenzaremos esta investigación exponiendo qué supuso el proceso de identidad nacional durante la posguerra y cuál fue su influencia en la escuela; para continuar presentando un recorrido por la literatura científica sobre identidad nacional en el franquismo. Terminaremos exponiendo el análisis de los datos y los resultados de nuestro trabajo.

\section{IDENTIDAD NACIONAL EN LA POSGUERRA}

La llegada de la dictadura franquista a España trajo consigo un cambio radical sobre la concepción de España y su ciudadanía, e incluso sobre la propia interpretación de su historia. Asustada por una Segunda República que conllevó el advenimiento de una nueva Constitución de carácter democrático, profundas reformas sociales y la conciliación del Estado con las autonomías regionales, la derecha española se erigió contra el proyecto republicano y durante casi tres años luchó contra él hasta exterminarlo (Boyd, 2000), saldándose la contienda con al menos 150.000 víctimas $^{1}$ (Casanova, 2014).

No obstante, la ideología contraria a los mencionados elementos que representaba la Segunda República no fue espontánea, sino que los nacionalistas españoles del bando sublevado tuvieron un caldo de cultivo ideológico que se remontaba varias décadas atrás, sobre todo a raíz de la guerra de Marruecos. En aquel momento se iría gestando en este sector la idea de que los partidos políticos y el parlamentarismo eran sinónimos de decadencia nacional (Fusi, 2000). Este sector conservador trajo consigo, durante la guerra civil y la posguerra, la defensa de «principios de orden, autoridad y unidad de los militares, [...] el pensamiento social de la Iglesia y [...] las ideas nacionalistas y fascistas de la Falange y la ultraderecha» (Fusi, 2003, p. 131). Para ello, el régimen asoció a la república y sus defensores términos como la «degeneración» innata, reflejo de su «naturaleza animal», y reconoció el "terror rojo» como único derivado de la contienda (Cazorla, 2007).

En definitiva, el franquismo supuso la convergencia de patriotismo y religión representada bajo el nacionalcatolicismo:

${ }^{1}$ La cifra de víctimas de la guerra civil es aún en nuestros días un dato desconocido. Autores como Fusi (2003) la elevan a más de 250.000 personas. 
Durante la Guerra Civil y la posguerra, desfiles militares, himnos, homenajes a los mártires y caídos, conmemoración de efemérides, saludos fascistas y narrativas palingenésicas confluyeron en Franco, asimilado a la figura de Cristo, a la nación española con la Virgen María y al Nuevo Estado con la resurrección de la patria y la restauración de los principios católicos. (Rina, 2017, p. 243).

En el ámbito educativo, ya desde el bienio radical-cedista se comenzaron a recuperar tradiciones como la fiesta de la raza, fuertemente promovida desde la dictadura de Primo de Rivera, u homenajes con tintes patrióticos a autores como Lope de Vega (Del Pozo, 2013). Posteriormente, y a partir de la guerra civil, se plantearía la creación de una nueva escuela española basada en los principios fascistas, los autores clásicos y las doctrinas expuestas en la encíclica Divini Illius Magistri, y se procedería al enmudecimiento de corrientes pedagógicas como la Escuela Nueva (Del Pozo, 2012).

Por otra parte, en los discursos y textos de la escuela franquista se instaló una versión de la historia de España de tintes triunfalistas con vocación imperialista y que buscaba acabar con la leyenda negra que pesaba sobre el país (Boyd, 2000). En la literatura escolar de la época, ya desde el conflicto bélico, era común leer fuertes críticas al republicanismo, los nacionalismos periféricos o la sociedad de naciones -generalmente desde autores e historiadores de clara inspiración católica-. Uno de los más representativos fue el manual de Agustín Serrano de Haro España es así, que se reeditó en múltiples ocasiones y en el que se podían leer afirmaciones tales como: «la República fue recibida con miedo y desconocimiento por la opinión sana de España» (Serrano, 1946, p. 286), «la masonería estaba muy arraigada en la República» (Serrano, 1946, p. 288) o "Y entonces, cuando ya todos los medios legales estaban agotados, surgió el hombre, el salvador, el caudillo» (Serrano, 1946, p. 289).

En conclusión, se podría concebir la guerra civil como una lucha de identidades nacionales y concepciones de España, cuya convivencia en la escuela republicana fue un hecho (Sanz y Rabazas, 2017). El resultado de este conflicto bélico implicó la búsqueda de un nacionalismo militante y autoritario y ligó la nacionalidad española a la religión católica y a una historia imperialista (Boyd, 2000).

\section{IDENTIDAD NACIONAL EN LOS AÑOS CUARENTA Y CINCUENTA. HACIA UN ESTADO DE LA CUESTIÓN}

A lo largo de los últimos años, diversas investigaciones han indagado en cómo fue transmitida la identidad nacional a la sociedad española durante el franquismo. El orden, la autoridad, el catolicismo y el patriotismo fueron aprendidos por los españoles a través de diversos medios culturales y educativos, que han sido objeto de estudio de un amplio volumen de publicaciones. A continuación, pasamos a realizar un recorrido por estos medios y a conocer las temáticas más estudiadas. 
Desde una primera revisión, apreciamos que el patrimonio histórico artístico (Cabrera, 2012; Tejerizo, 2012), así como los paisajes de la geografía española, plagados de hechos pasados, mitos, hazañas y memoria histórica, se convierten en uno de los objetivos para la construcción de la identidad nacional, por el régimen (Torre, 2002; Box, 2016). La «Nueva España», surgida tras la guerra, es representada a través de elementos geográficos y culturales enraizados en la tradición española (Lemus, 2013), a través del turismo y la fotografía (Ramón y García, 2016).

No es casualidad que, desde esta construcción política de la identidad española (Muñoz, 2012), la tradición cultural juegue un papel decisivo. Las fiestas nacionales, cargadas de intenciones políticas y enraizadas en determinados imaginarios sociales, serán los ejemplos de la identidad nacional española y así se proyecten a nivel internacional (Giori, 2014; García, 2016). El folclore (Casero, 2000; Mora, 2015; Criado, 2017), los toros y la música española (Iglesias, 2010; Piñeiro, 2013; Otaola, 2015), servirán para propagar los valores tradicionalistas a lo largo de la dictadura, dentro y fuera de las fronteras españolas (Storm, 2013). Estas tradiciones están solapadas con la religión, núcleo central del ideario nacional de aquellos años, que se hace patente en cada foco de investigación (Boyd, 2000; Hasting, 2000).

La representación geográfica y cultural es contemplada desde los ejemplos de la «nación vivida», para los españoles que nacieron y se criaron durante el primer franquismo (Fuertes, 2012); y la "nación evitada», para aquellos que tuvieron que huir de ella (Navarro, 2016). Esta última visión también se hace patente en los estudios que abordan las tensiones entre la identidad nacional y la identidad regional (Núñez, 2006). Dentro de ellas, regiones como el País Vasco (Molina; 2005; González, 2013; Gómez, 2015) o Cataluña (Geniola, 2011; Giori, 2014), serán algunas de las zonas más investigadas, tanto por su identidad lingüística como por sus continuas disputas entre identidad territorial y nación (Morillo, 2015).

La instrumentalización política de la cultura franquista (Colomer, 2015; Ferrer, 2012), también se hace perceptible a través del consumo de contenidos audiovisuales en radio (Gómez, 2009) prensa (Melloni y Peñamarín, 1980; González y Limón, 1988; Peñamarín, 2002; Soriano, 2011), cinematografía (Labanyi, 1999; Gutiérrez, 2000; Menéndez y Medina, 2003; Ortega, 2014) y televisión (Durante, 2014). Considerados por la dictadura como principales objetivos para el adoctrinamiento civil, estos medios ayudarán a propagar un gran control social e ideológico sobre las masas.

El deporte también fue utilizado como elemento de transmisión de la identidad nacional por el franquismo (Manrique et al., 2009). El ciclismo (Ródena, 2012), la pelota vasca (Gómez, 2015) y especialmente el fútbol (González, 2014), fueron actividades capitalizadas por el régimen como vehículos difusores del nacionalismo a través de los que reforzar la identidad colectiva. La creencia en el progreso, la exaltación de la disciplina, el heroísmo cuasi-militar y la unión de valores e intereses entre el deportista y la afición, posibilitaban un sistema coherente y sólidamente estructurado para transmitir representaciones colectivas (Fernández, 1990). 
También desde el deporte, la infancia (Palacio y Ruiz, 1993; Souto, 2015) y la juventud (Manrique, 2011 y 2014) se convirtieron en los grupos sociales más atractivos para el Gobierno franquista. El adoctrinamiento de los jóvenes pretendía consolidar el ideario franquista y conservar su hegemonía en el tiempo.

El género toma un papel esencial en el moldeamiento de las masas juveniles, para el que opera no solo el Estado, sino también la Iglesia (Sanchidrián, 2004; Badanelli, 2005; Garbayo, 2016; Moreno, 2017). Estudios biológicos, médicos y bíblicos amparaban la teoría nacional-catolicista sobre las diferencias entre lo masculino y lo femenino, justificando un sistema de organización sexista en el que el protagonismo femenino quedaba reducido al hogar (Manrique, 2007 y 2014; Bergès, 2012). Profesiones como el servicio doméstico, el magisterio o la enfermería -en detrimento de otras como la literatura (Abdulla, 2012)-, ocupaban al mayor número de mujeres empleadas en aquellos años (Chamizo, 2009; Manrique et al., 2009; Rabazas, 2001).

Son innumerables los estudios que se ocupan de estudiar las relaciones entre la escuela, el nacionalcatolicismo y el género durante el periodo franquista (baste con citar Navarro, 1993; Escolano, 2006; o Mahamud, 2010). Dentro de este foco de estudio sobre el ámbito escolar, ocupan un interés prioritario los documentos escritos. Quizá, como apunta Banadelli (2008), este interés radica en que la difusión del patriotismo constituyó un objetivo prioritario para el régimen, pues la ideología franquista solo podía consolidarse a través de un sistema educativo capaz de difundirla, como parte de un proceso más de uniformización cultural de la población. De esta forma, los manuales escolares (Araujo, 2003; Somoza, 2005; Valls, 2009; Sanz y Rabazas, 2017), los libros de texto y lecturas (Badanelli, 2008; Inarejos, 2013) y, recientemente, los cuadernos escolares (Sánchez, 2004; Martín, Ramos y Hernández, 2010; Badanelli y Mahamud, 2011; Sanchidrián, 2013; Dávila y Naya; 2015) y las fotografías (Sonlleva, Sanz y Torrego, 2018), constituyen un interesante instrumento desde el que analizar cómo se gestó la homogeneización social en las escuelas a través de mecanismos cognitivos, identitarios y afectivos.

Este recorrido por las publicaciones sobre nuestro objeto de estudio nos permite concluir exponiendo que, aunque las investigaciones sobre la construcción de la identidad nacional en el franquismo no son nuevas, los estudios monográficos que abordan este concepto desde la historia oral han comenzado a proliferar en los últimos años. Colmeiro (2005) destaca la importancia que tiene la investigación de la identidad cultural a través de la recuperación de relatos orales y así lo muestran trabajos como los de: Font (2004), que profundiza en el conocimiento de las actitudes políticas en el franquismo a través de fuentes orales; Pedrero y Piñero (2006) que recapitulan algunas experiencias femeninas de posguerra; Rodríguez (2008) que investiga sobre los secretos de la represión franquista en Almería; Zabaleta, Garmendia y Murua (2015) que utilizan testimonios directos de protagonistas del movimiento popular, para abordar la identidad nacional en la escuela vasca; Cucó 
(2016), que los utiliza para recuperar la visión del Movimiento Comunista; o Barceló y Montes (2016) que recogen las voces de algunas matronas catalanas para profundizar en el modelo de asistencia al parto en el franquismo.

En la investigación sobre la escuela de la posguerra con testimonios orales, son muchos los estudios que toman a la figura del docente como principal narrador de la historia escolar (Ramos, 2007; Guichot, 2009; Leite, 2011; Domenech, 2016), pero son más escasos los que escuchan la voz de los estudiantes de aquellas escuelas (Bedmar y Montero, 2010; Sonlleva y Torrego, 2014; Sonlleva, 2016 y 2017). Como apuntábamos al inicio de este trabajo, el valor de estas fuentes orales resulta fundamental si pensamos que aquellos escolares de posguerra portan entre sus recuerdos las heridas de una enseñanza que marcó las formas de pensar, de sentir y de ser de varias generaciones.

\section{CONSIDERACIONES METODOLÓGICAS}

Nuestro trabajo, desde hace algunos años, se centra en recuperar la memoria histórica de los escolares de posguerra. Las fuentes orales significan para este estudio el potencial hermenéutico de la memoria hecha y deshecha de lo vivido (Fraser, 1993); una memoria que está llena de olvidos, construida a base de silencios y de parches que han ido ajustándose a las necesidades del presente (Colmeiro, 2005).

Los niños y las niñas, especialmente aquellos que pertenecieron a clases populares ${ }^{2}$, son los testigos vivos de la dictadura que más sufrieron la violencia y la represión después de la guerra. Cada pequeño fue testigo de un drama social y personal cuyo recuerdo circuló durante la transición y la democracia, por una España teñida por el miedo y el olvido (Torres, 2006). El testimonio de estos informantes es fundamental para recomponer la historia franquista, pues, como apunta Sofía Rodríguez, aún en nuestros días, existe una parte importante de la sociedad que se encuentra incómoda ante las versiones de los hechos representados por la historiografía tradicional.

El desigual acceso a la formación, y a la información, causado fundamentalmente por razones de clase social, y el vivir todavía en una cultura donde se concede mayor rango, o credibilidad, al testimonio escrito que al oral, provoca que algunas versiones de los hechos, acalladas desde 1939, apenas se hayan tenido en cuenta a la hora de reconstruir la historia (Rodríguez, 2008, p. 263).

${ }^{2}$ La delimitación del concepto clases populares toma fines diferentes en la historiografía. En nuestro caso, tomamos esta noción para referirnos a las personas de los sectores productivos, ajenos al mundo del privilegio y del poder (Lida, 1997). 
Nuestro interés es recuperar algunos de esos relatos y profundizar en las emociones y experiencias de la etapa infantil, para conocer cómo fue aprendida la identidad nacional a través del contexto educativo y social. Los testimonios de dos hombres y dos mujeres nacidos en la década de 1930 en familias de clase popular guiarán nuestro análisis. Los relatos de vida fueron realizados entre los años 2013 y 2016 y contemplan un total de 23 entrevistas, con más de 250 páginas de transcripciones.

Abordaremos el análisis narrativo tomando como referencia los temas más significativos -en torno al concepto de identidad nacional-, que hemos encontrado en las investigaciones anteriormente citadas. Para organizar la información, hemos categorizado los datos a través del programa informático ATLAS.ti de análisis cualitativo, estableciendo dos categorías primarias: escuela y sociedad ${ }^{3}$. Estas dos primeras categorías se han establecido por ser los dos temas más repetidos en los testimonios y, desde ellos, se agrupan algunos temas secundarios. De esta forma, en relación al conocimiento de la transmisión de la identidad nacional a través de la escuela, analizaremos: la simbología en la escuela, las rutinas y materias escolares y la figura del docente. Desde el contexto social, estudiaremos: las relaciones familiares, los poderes locales y la cultura, las fiestas populares y el folclore.

Narraremos cada uno de los apartados mencionados con anterioridad desde las voces de nuestros protagonistas, tomando su relato en primera persona. Junto a sus palabras aparecerá su nombre, y el número de entrevista (e. 1, 2, 3...) en la que se recoge el extracto de la cita. Esta forma de análisis ayuda al lector a conocer la vivencia individual de cada protagonista, a través de un narrado polifónico.

Antes de comenzar la exposición de resultados, hemos creído conveniente realizar una breve presentación biográfica de cada uno de los participantes, con el objetivo de que el lector pueda contextualizar su experiencia y que a lo largo del análisis reconozca su voz individual.

Felisa.

Nació en el año 1937 en Hontoria, un pequeño pueblo de la provincia de Segovia. Nacida en familia de labradores, fue la única superviviente de cinco hermanos que resistió a la guerra. A los seis años, comienza su experiencia escolar en la escuela pública de su localidad natal, en el aula femenina. Abandona su escolaridad con 14 años, tras terminar la Educación Primaria. Su vida adulta transcurre cuidando a sus hijas, realizando las tareas domésticas y ayudando a su marido en las faenas del campo.

${ }^{3}$ La diferenciación entre las categorías de escuela y sociedad no ha sido sencilla, pues se hace complicado separar algunos acontecimientos y experiencias de los narradores que podrían incluirse en ambos contextos, como, por ejemplo, la celebración de rituales religiosos o fiestas escolares vinculadas con la religión. 
Gloria.

Nació en el año 1937 en Losana de Pirón (Segovia). De familia de comerciantes y labriegos, pasa su infancia en compañía de siete hermanos. Comienza su escolaridad a la edad de seis años, en la escuela pública mixta de la localidad y la termina con catorce, tras obtener el Certificado de Estudios Primarios. Tras su experiencia escolar, sus padres le permiten que aprenda costura en una academia de Madrid y consigue la titulación de "Maestra de Corte y Confección». Su vida adulta transcurre en el pueblo de su marido, encargándose de las labores domésticas y el cuidado de su hijo.

Gregorio.

Nació en el año 1933 en un barrio del centro de la ciudad de Segovia. Su madre era ama de casa y su padre cocinero en la Academia de Artillería. Vivió su infancia con cuatro hermanos, tres varones y una mujer. Comienza su escolaridad a la edad de ocho años en una escuela pública de niños, cerca de su casa. Abandona el colegio al terminar la Educación Primaria, con 14 años. Después de su experiencia escolar, estudia (en la escuela de oficios) carpintería. Años más tarde, contrae matrimonio y dedica su vida adulta al trabajo como transportista.

Modesto.

Nació en el año 1935 en Revenga, un pequeño pueblo de la provincia de Segovia. De familia de labriegos y gabarreros, pasa su infancia con cuatro hermanos, tras haber perdido a cinco de ellos durante la guerra. Su etapa escolar es reducida (desde los seis hasta los nueve años), pues la pérdida de su hermano mayor le obliga a tener que colaborar de forma activa en la economía familiar. Son numerosos los trabajos que desempeña en su juventud: gabarrero, obrero, labriego... Su vida adulta, tras casarse con su esposa y tener dos hijos, está dedicada al mantenimiento económico de la unidad familiar.

\section{ESCUELA Y SOCIEDAD EN LA POSGUERRA. LA IDENTIDAD NACIONAL A TRAVÉS DE FUENTES ORALES}

La identidad nacional se convirtió en un elemento crucial para la supervivencia de la unidad política en España tras la guerra. La estrategia nacionalizadora del Gobierno franquista tenía como último fin garantizar el apoyo de la población al régimen. En este contexto, las instituciones y la nueva elite nacida tras la ofensiva tenían la misión de legitimar la idea de patriotismo y readaptarla al nuevo contexto 
(Muñoz, 2012). La promoción de una única lengua, una insuperable cultura y una excelente base religiosa solo podía ser efectiva a través del adoctrinamiento de las masas. Por ello, la institución educativa fue objeto fundamental del régimen franquista desde el comienzo del conflicto armado. La escuela se bautizó como una instancia privilegiada para la transmisión ideológica del Nuevo Estado. Los valores religiosos y patrios fueron los estandartes de la Educación Primaria de posguerra (Palacio y Ruiz, 1993).

\subsection{Aprender la identidad nacional en la escuela...}

La escuela fue uno de los lugares en el que los niños y las niñas de posguerra, vivieron un importante periodo de su infancia.

Empezábamos el colegio a los seis años y solíamos estar allí hasta los catorce. A diario, íbamos al colegio mañana y tarde. Por las mañanas íbamos de nueve a una de la tarde; y por las tardes de tres a cinco... Ese horario le solíamos mantener, si no me equivoco, de lunes a sábado (Gloria, e. 2).

Es esa cantidad de tiempo vivido dentro de la institución educativa la que permite recordar a los protagonistas, con facilidad y detalle, lo que ocurre dentro de los espacios escolares.

Simbología en la escuela

La carga simbólica que aparece dentro de la institución escolar es abundante. La bandera, el escudo, el yugo y las flechas, así como los retratos del general Franco o José Antonio Primo de Rivera, constituyen símbolos oficiales que están presentes en todas las escuelas de España tras la guerra (Sanchidrián y Arias, 2013). Esta simbología se ve representada en los testimonios de los participantes:

El cuadro de Franco, el de José Antonio Primo de Rivera, el yugo y las flechas y una cruz (...) eso estaba en una pared...; y en la de enfrente estaban la pizarra y los mapas (Gloria, e. 5).

La representación de estos elementos nacionales estaba regulada a través de disposiciones decretadas entre 1936 y 1938 y, junto a ellas, se hacía obligatoria la presencia de simbología religiosa (Pozo y Rabazas, 2010). El crucifijo y la imagen de la Inmaculada Concepción adornan, desde finales de los años treinta, las escuelas españolas. 
Recuerdo que, en la pared frontal, donde se sentaba la profesora y estaba el encerado, estaba una fotografía de la Virgen de la Purísima, un crucifijo y la fotografía de Franco (Felisa, e. 1).

Identidad nacional y religión se conciben, en los primeros años del franquismo, como términos solapados (Hastings, 2000). Su estrecha relación se debe a la conjugación del ideal católico y la monarquía militar que representó el nacionalcatolicismo (Boyd, 2000).

A la simbología religiosa y nacional presente en el aula, se unen los mapas de España. Estas proyecciones consolidan la idea de territorio y transmiten el concepto de centralismo, a partir del cual se vinculan otras nociones como el catolicismo o el patriotismo (Sanchidrián y Arias, 2013).

En la pared también estaban colgados dos mapas. Eran solo de España. Había uno de provincias y otro de ríos y montañas (Modesto, e. 2).

Adoctrinamiento político y religioso a través de las rutinas y las materias escolares

Esta fusión entre nación y religión se aprecia también a través del adoctrinamiento vivido en las rutinas del aula y los materiales escolares utilizados. Cada mañana, los menores entraban al aula realizando algunos rituales que iban amaestrando sus dóciles conciencias infantiles.

La profesora era la que abría todas las mañanas la escuela, a las nueve. Nosotros entrábamos detrás de ella, nos santiguábamos y teníamos que rezar un "Padre Nuestro» y un «Ave María» (Modesto, e. 1).

La religión no solo se hace patente al inicio de la jornada escolar, sino que impregna todo el currículum.

La religión la trabajábamos todos los días, por la mañana o por la tarde. Leíamos lo que venía en el catecismo y en aprendíamos la lección del libro de Historia Sagrada: sacramentos, oraciones, mandamientos... (Felisa, e. 1).

La presencia de la religión también se constata desde los materiales escolares. Por la Orden de 8 de septiembre de 1936, la inspección autorizó el uso exclusivo de obras cuyo contenido respondiese a los principios de la religión y moral cristiana, exaltando el patriotismo de la niñez. 
Cada niña teníamos una enciclopedia, un libro de Historia Sagrada y un catecismo (...). La maestra también nos traía de su casa, cuando éramos pequeñas, unas cartillas para aprender a leer (Felisa, e. 3).

La fuerza del nacionalcatolicismo es inculcada a través de estos libros escolares. Autoridades políticas y eclesiásticas (fundamentalmente masculinas), son presentadas a través de los textos como héroes y maestros, dotados con el don de la infalibilidad (Badanelli, 2008).

Nosotros solo dábamos lo que hacía referencia a la Historia de España, también, la hispanidad, el descubrimiento de América, por Cristóbal Colón (...), y la vida de todos los Santos (Felisa, e. 4).

En los testimonios también aflora el recuerdo de las lecciones sobre España y lo español. En ellas es innegable el valor que se da a la unidad y el tradicionalismo, dos aspectos que permitían recuperar la grandeza de la nación, bajo un modelo imperial, católica y centralizado (González y Lion, 1988).

Me acuerdo de alguna noción que nos daban sobre España, por ejemplo, cómo eran las banderas nacionales y de la Falange. Nos decían que la de la Falange era con fondo negro y el signo falangista en color rojo; y la bandera española era roja y amarilla, y quería decir sangre y oro (Goyo, e. 4).

Las lecciones sobre la bandera española y lo que esta representa quedan marcadas en la conciencia de los más pequeños. Junto a ellas aparecen algunas nociones sobre Formación Política, Geografía e Historia de España, desde las que se impone la unidad y el centralismo (Badanelli, 2008, p. 146).

Solo se estudiaba la geografía española, desde Andorra para abajo, lo demás no interesaba, solo para abajo (Goyo, e. 3).

Los mapas que había en clase eran solo de España. Había uno de provincias y otro de ríos y montañas... Nos enseñaban los ríos y las capitales (Modesto, e. 2).

Luego, teníamos que dibujarlos nosotros en el cuaderno y poner las cordilleras y los ríos (Gloria, e. 2).

Las consignas políticas -como frases emotivas, breves y adaptadas al nivel mental del alumno- incitaban al aprendizaje de ciertos contenidos patrios que calaban en la memoria de los estudiantes (Sanchidrián y Arias, 2013). Así lo hemos podido comprobar desde los datos analizados: 
En clase solo estudiábamos la Historia de España. No hablábamos de mucho que no fuera el franquismo. Recuerdo que, una vez, empezamos un dictado escribiendo: «El Alzamiento Nacional fue completamente necesario, espontáneo y justo» (Felisa, e. 4).

Otra de las materias con un fuerte poder adoctrinador fue la Educación Física. Esta asignatura solo aparece en el relato de Gregorio, cuya experiencia escolar se contextualiza en una escuela urbana. Quizá, esto se debe a que la Educación Física en general (y la femenina, en particular), se encontraban durante la posguerra "en mantillas» (Manrique, 2003, p. 90). Las palabras de nuestro participante resultan esclarecedoras para conocer una aproximación hacia la figura del profesor de Educación Física y la actividad que los niños realizaban en estas clases.

Recuerdo que, la clase de Gimnasia, la dábamos un día a la semana y solo duraba una hora, aunque para lo que hacíamos... sobraba tiempo. Creo que era, en concreto, los jueves. Nos llevaban a un gimnasio, con un profesor que tenía una uva el tío... Me acuerdo que tenía un florete, con el que practicaba esgrima, y al que le veía un poco más así, o que no le gustaba lo que estaba haciendo, iplas!, un latigazo con el florete en las costillas (Goyo, e. 1).

Parece que la actividad física que realizaban los niños se asemejaba a un tipo de educación premilitar, que se concretaba en la adquisición de algunas virtudes concordantes con los principios ideológicos nacionalsindicalistas, como la obediencia, la jerarquía, la disciplina o el servicio a la patria (Manrique, 2014).

A nosotros nos ponían en fila y nos mandaban alinearnos con el compañero de delante. Luego, teníamos que poner los brazos en cruz, levantarlos hacia arriba, agacharse, levantarse, ponerse en jarras y echar el cuerpo hacia la derecha, hacia la izquierda... Esa era la gimnasia que hacíamos (Goyo, e. 4).

Para las niñas, la asignatura más nombrada en los testimonios es «Enseñanzas del hogar». A través de esta materia, las maestras preparan a las jóvenes para el hogar y la familia (Rabazas, 2001).

Por la tarde, hacíamos costura o cantar. Todas las tardes cogíamos nuestro costurero y -los meses que hacía frío- dentro del aula; y-los que hacía bueno- a coser a la calle, con la maestra. En estas clases de costura nos enseñaban a hacer crucetilla, a bordar, a hacer costuras, a hacer calados... Todo el año haciendo lo mismo. Luego, lo que hacíamos allí, nos lo llevábamos a casa (Felisa, e. 3).

En este horario vespertino, niños como niñas eran instruidos en el aprendizaje de algunas canciones. Desde el recuerdo de algunas de ellas aparece el himno nacional. 
No, nosotras el «Cara al sol» no le cantábamos en clase (...), pero lo cantaban los chicos, eso sí «cara al sol con la camisa nueva... que tú bordaste en rojo ayer. Me hallará la muerte si me lleva y no te vuelvo a ver». Sí, sí, la oído varias veces, ese era el himno de la Falange (Felisa, e. 4).

Junto a las canciones que despertaban el amor patrio, aparece el recuerdo de otras letrillas y versos -aprendidos en la escuela-, vinculados directamente con la religión.

Lo de aprender versos era muy normal (...) nos los enseñaba la maestra y teníamos que aprenderlos de memoria. Recuerdo uno que decía así: «Aunque soy tan pequeñita y tengo tan poquita voz, nadie me gana a decir iViva la madre de Dios!» (Felisa, e. 4)

Los versos y las poesías, en honor a la Virgen María, son especialmente recordados durante el mes de mayo.

En el mes de mayo, por las tardes, ensayábamos el himno a la Virgen y la llevábamos flores. Llevábamos un ramito de chiviritas y amapolas, que era lo único que había, y cantábamos la canción de «Venid y vamos todos con flores a María» (Goyo, e. 1).

El calendario escolar se confeccionaba teniendo en cuenta las fiestas religiosas y nacionales. Son varias las festividades que los niños y niñas recuerdan en relación a estas efemérides, pero resultan relevantes, por su poder adoctrinador, la Semana Santa y la conmemoración de la muerte de José Antonio Primo de Rivera.

En Cuaresma no íbamos al colegio (...). Los Santos se tapaban, con unos paños morados, y, hasta que no pasaba la Cuaresma, no se destapaban... Eso se hacía porque estábamos en tinieblas... Me acuerdo que se tocaba con las carracas y los carracones, para que pudiera ir la gente a la iglesia; y, durante esos días, no se tocaban las campanas. Hasta que no se llegara la Resurrección no se podía hacer nada. En esos días teníamos que ir a los sermones (...). A mí eso me daba de pequeña un poco de miedo... Me acuerdo que veías a los Santos, veías todo y... te asustabas (Gloria, e. 2).

A José Antonio le habían matado al poco tiempo de entrar yo a la escuela, porque íbamos a misa por el aniversario de su muerte. Teníamos que ir a misa de forma obligatoria ese día, todos los chicos y las personas que vivíamos en el pueblo (...). En la piedra que había en la fachada de la iglesia, había una inscripción de José Antonio (...). Estaba en la misma esquina de la iglesia, en un trocito de cemento liso. Ese día, el alcalde siempre iba con la camisa azul (Felisa, e. 4).

A través de estas enseñanzas, desde la escuela, el maestro mostraba a sus alumnos el camino que estos debían seguir como buenos españoles católicos (Martín, Ramos y Hernández, 2010). 


\section{La figura del maestro y la maestra}

Ser español implicaba, en aquellos años de posguerra, religiosidad, rigidez y militarismo. Los militares habían sido los ganadores de la guerra; y la sumisión al Ejército, así como la defensa a la patria, eran contenidos primordiales en el repertorio escolar (Navarro, 1990). La violencia que ejercía el docente hacia los escolares aparece reflejada en cada una de las memorias de los participantes. Mostramos un ejemplo de este tipo de actitudes, a través del siguiente extracto de entrevista:

El maestro iba así paseando por los pasillos de la clase, viendo quién hacía los deberes o no los hacía. De pronto, te ponía la mano encima de la cabeza, como que te iba a acariciar. Le mirabas y a lo mejor le preguntabas -¿qué pasa?- (pensando que te iba a acariciar), y te cogía y te pegaba un tirón de orejas. Le decías -profesor, ¿por qué me ha hecho eso?, si yo no he hecho nada ahora-; y te decía -ipero lo he hecho yo! y como soy el que mando aquí, hago lo que me da la gana- (Goyo, e. 4).

El maestro ejercía su papel autoritario en el aula, sembrando el miedo entre su alumnado.

No sé si tenía miedo al maestro o a la reacción que pudiera tener... Yo pensaba iy este hombre qué me va a hacer! Si me llamaba, era porque no iba a pasar nada bueno (Gloria, e. 1).

La figura de la maestra también era un ejemplo de autoridad en el aula. El contacto físico y la muestra de afectos, entre alumna y maestra, no era una práctica habitual.

La maestra no era muy cariñosa. Nos dábamos los «buenos días» por la mañana y nos despedíamos por la tarde, pero no había contacto físico. No había abrazos. Esta maestra no era mala, pero, vamos, si te tenía que meter un tortazo, te le metía (Felisa, e. 1).

Los principios de autoridad y jerarquía presidían todas las relaciones escolares. Los castigos físicos formaban parte de este proceso y llegaron a aceptarse como conductas normales (Escudero, 2007).

Los castigos iban, desde pegarte un capón, tirarte de los pelos, ponerte los brazos en cruz llenos de libros y darnos reglazos en las manos. Y lo de los libros era horrible, porque te ponía encima de cada mano tres o cuatro libros, de los más gordos que hubiera en clase, y tienes que tener en cuenta que, con los brazos en cruz, llegaba un momento que el peso se hacía insoportable y los brazos se te caían, quisieras o no... Y como se te cayeran, ite pegaba unos reglazos en la mano!, ipara que te espabilaras! (Goyo, e. 4). 
Las familias no reprendían las conductas autoritarias del maestro, su poder traspasaba la línea de dominación de los propios estudiantes.

Los padres, en vez de defender a los hijos, defendían al maestro. Mis padres me decían -tú hijo, cállate y haz lo que te manden. Haces las tareas y todo lo que ellos te manden-. Desde luego, a aguantar y a callar, eso era lo que nos enseñaban nuestros padres (Goyo, e. 1).

Junto al maestro y la maestra, el sacerdote ocupa un lugar referente en los recuerdos escolares de los participantes:

Él (haciendo mención al sacerdote) nos enseñaba cosas de la Iglesia... Teníamos que aprender el Padre Nuestro, los Credos, el Ave María... y nos daba algo de catequesis, de cara a la comunión. Venía muchas veces a la escuela (Modesto, e. 2).

Junto al sacerdote, el maestro y la maestra constituían un ejemplo de religiosidad para los pequeños, y así se lo inculcaban a través de diferentes actos sociales:

Teníamos que ir a buscar, todos los niños y niñas, al maestro o a la maestra a su casa; y acompañarles los domingos a misa. Ese camino, hasta allí, le hacíamos cantando... Llevábamos una cruz, que la vestíamos todos, el día tres de mayo, que hacíamos la fiesta de los niños (Gloria, e. 1).

Precisamente, es esta vinculación entre la escuela y otras instituciones, como la eclesiástica, la que nos advierte que la escuela no está separada de su contexto, y así lo hemos apreciado en las narraciones de los participantes. La construcción del conocimiento que tiene lugar en el niño no se produce de forma aislada en la escuela, sino que también depende de las posibilidades que este encuentre y el medio en el que se desenvuelva (Sanchidrián y Arias, 2013). Desde esta perspectiva, nos disponemos a ampliar el conocimiento de la identidad nacional, recorriendo, a través de la voz de nuestros participantes, algunos temas sociales enlazados con la misma.

\subsection{Identidad nacional y aprendizaje social desde la mirada infantil}

Infancia, relaciones familiares y trabajo

Siguiendo la tradición y la costumbre, los niños y niñas eran educados moralmente desde la infancia. La familia transmitía algunos consejos y normas de conducta en los que imperaba la obediencia y el respeto a los mayores (Sánchez, 2004). 
Cuando eras niña, siempre tenías que respetar a la gente más mayor que tú, ya bien fueran hombres o mujeres. Eso antes era un valor importante que te enseñaban desde pequeño... (Felisa, e. 6).

En esta relación con los mayores, dentro del propio núcleo familiar, el padre se presenta como la autoridad suprema del hogar. Los hijos le deben sumisión y respeto.

Mi padre trabajaba todos los días, de lunes a domingo, y nosotros no pasábamos tiempo en familia. Mi madre nos sacaba a un jardín, que había en el barrio, y allí jugábamos (...). Con mi padre no se podía contar, bastante tenía con lo suyo (Goyo, e. 3).

La figura del hombre era de miedo para la mujer, todo debía estar hecho cuando él llegaba (Felisa, e. 2).

La imagen de la madre se encuentra subordinada a la del varón. Las actitudes de cuidado, debilidad y sentimentalismo con la que los protagonistas hablan de esta figura materna, se reflejan en todos los testimonios.

Pobrecilla... Me acuerdo de mi madre, que se levantaba a las cuatro de la mañana o antes, para hacer un almuerzo antes de que se vinieran a Segovia (haciendo alusión a su padre y a sus hermanos) (...). Y luego tenía que hacer las cosas de casa, la comida, la tienda... (Gloria, e. 2).

Los pequeños iban aprendiendo cuál era el papel de cada miembro en el hogar y reproducían, a través de sus conductas, los patrones que les marcaba la familia según su sexo:

La mujer debía preocuparse de la educación de los hijos y de tener todo en orden cuando llegara el marido. El hombre, pues se dedicaba a ir a trabajar y a traer un jornal a casa, para que se pudiera mantener la familia, pero no colaboraba en las cosas de casa. Los papeles estaban muy bien asignados para todos los miembros de la familia; y, luego, los hijos, pues ya sabían, a ayudar a los padres en cuanto pudieran, ya bien haciendo alguna tarea con la que pudieran quitar a los padres trabajo; o ya bien marchando a trabajar para poder aportar un pequeño jornal para comer (Goyo, e. 5).

Esta idea de hombre trabajador es congruente con la que transmite el nacionalcatolicismo y así se enseña a los niños a través de la familia (Badanelli, 2008, p. 153). 
Los niños, cuando valían para trabajar, la familia los empleaba. Algunos dejaban el colegio, como yo, con ocho o nueve años; y otros llegaban a estar allí hasta los doce, pero nada más... Me acuerdo que, los niños, solían ir de vaqueros o a ayudar a sus padres si tenían algo de labor (Modesto, e. 1).

El trabajo duro era cosa de hombres. Este tipo de actuaciones le dignificaban y le honraban. A través de ese espíritu valiente y sacrificado, el hombre se convertía en el referente del ámbito público (Somoza, 2005).

Yo empecé cobrando, la primera vez que trabajé, a la semana, siete duros... picando, con un pico y una pala, para hacer carreteras en el pinar. Como era muy joven (date cuenta que tendría unos doce años más o menos) (...) me acuerdo que me llevaba un burro y, como estábamos por el pinar, a la que volvíamos me bajaba una carga de leña (Modesto, e. 1).

Algunos jóvenes, a través del internamiento en el Seminario, tenían la opción de continuar los estudios después de la escuela. Las posibilidades académicas para las niñas, después de la escuela, eran minúsculas. Su lugar estaba en el hogar.

No conozco a ninguna mujer que siguiese con sus estudios después de la escuela; en cambio, de hombres de mi edad, sí, al menos recuerdo a cuatro que hicieron estudios de Bachillerato. También hubo chicos que lo que sí hicieron, fue estudiar para ser curas, en el Seminario. Estos chicos provenían de familias pobres, pero destacarían en los estudios y sus familias decidieron animarles para que siguieran estudiando. Era una buena salida para poder estudiar (Felisa, e. 1).

El Fuero del Trabajo de 1938 reconoce a la familia como célula primaria de la sociedad y otorga a la mujer máximas competencias dentro del hogar. Como apuntan Manrique et al. (2009), esta concepción hace que no tenga ningún sentido que la mujer busque otros caminos de reconocimiento social y económico, pues en la familia se desarrollan todas sus expectativas sociales.

Las hijas, generalmente, si podían estarse en casa, se quedaban en casa ayudando a la madre; y si no, pues se iban a servir a familias con un poco más de recursos, profesores, militares o gente de esta, que tenía algo más de dinero que la gente más humilde (Goyo, e. 5).

La limpieza o el aprendizaje de los rudimentos del hogar eran las actividades a las que más horas dedicaban las niñas después de la etapa escolar. El objetivo de estos aprendizajes pasaba por que la joven fuera asumiendo las actividades que 
realizaría en su vida adulta; y, además, que interiorizara su inferioridad y conformismo para su futuro papel dentro del matrimonio.

Cuando salías de la escuela, te mandaban a aprender a coser o a hacer labores domésticas. Cualquier cosa que no fuera eso, no interesaba; $y$, después, buscar una pareja, casarte y tener hijos y, claro, cuidar a tus padres cuando eran mayores (Felisa, e. 1).

A través de estas actividades la mujer aprende su «importante» labor en el hogar y va apartándose del espacio público. Las protagonistas reconocen que el matrimonio supuso para ellas un importante cambio en sus vidas; y que, a partir del mismo, empezaron a sentirse como «esclavas del hogar».

Me casé joven y, luego, ya no era lo mismo. La mujer pierde todo. La mujer no podía salir con sus amigas. Antes, la mujer estaba muy sumisa. Su vida pública se olvidaba cuando se casaba y el hombre... hacía lo que le daba la gana. La mujer era una esclava, estaba de esclava, no tenía libertad para nada (Felisa, e. 2).

Por el contrario, el hombre, al contraer matrimonio continúa teniendo una mayor presencia en la esfera pública.

La mujer no tenía derecho a nada, nada más a trabajar (...). Me acuerdo que los hombres podían echar la partida los domingos, allí en la taberna; y las mujeres se ponían a coser o hacer otra cosa de casa (Gloria, e. 2).

La asistencia a los actos religiosos y la costura, en compañía de las vecinas, son las únicas actividades sociales para muchas mujeres españolas de los años cincuenta, especialmente para aquellas que viven en entornos rurales.

Las vecinas, las que vivíamos cercanas, sacábamos una banqueta a la puerta y allí hablábamos y hacíamos las labores... Esto lo hacíamos desde pequeñas (...) y en esos corros se hablaba de lo que pasaba en el pueblo, porque allí no había otra cosa de hablar (Gloria, e. 2).

Poderes locales: sacerdote, Guardia Civil, alcalde...

En la asunción de estas ideas doctrinarias de género y clase, tuvieron un importante papel algunas figuras sociales de especial relevancia a nivel local en aquel periodo. El sacerdote, la guardia civil y el alcalde no solo jugaron un papel fundamental en la depuración del magisterio, sino que ejercieron un fuerte control y 
represión sobre la población con menos recursos. El recuerdo de esta represión se refleja en las memorias de nuestros participantes:

Los guardias iban por las casas, a buscar a la gente que tenía ideas contrarias. Les subían en unos camiones y se les llevaban para matarles hacia la sierra. A la madre de un primo mío, allí, en la misma puerta de su casa, la dejaron, allí la mataron. Iba a salir a la compra y ila asesinaron en la puerta! Y a un hermano de la madre de mi mujer, tiraron una bomba y le dejaron sin piernas... En cuánto salían y veían a alguno así, de mala manera, le pegaban dos tiros y allí le dejaban (Goyo, e. 2).

El miedo es un sentimiento constante que aparece en cada relato de vida. Uno de los informantes nos explica el tipo de represalias que podía conllevar el tener un ideario político alejado del impuesto por el Gobierno franquista.

Mucho, mucho miedo... Me acuerdo que no se podía hablar de nada... El que hablaba entonces, de política, ya se podía mirar muy bien de lo que decía, porque estaba en peligro. No es como hoy; entonces, te cogían y si te veían hablando de esos temas, te metían una paliza y te metían a la cárcel jo te mataban! (Modesto, e. 2).

Los niños y las niñas eran adiestrados en el temor hacia ideas socialistas o comunistas no solo desde el ámbito escolar, sino también a nivel social.

Me estoy acordando de los comunistas, los que llamaban «los comunistas». Me acuerdo que nos metían miedo... Nos decían que, esos hombres, nos iban a matar a todos, que había que tener cuidado con ellos (Modesto, e. 2).

Pronto, estas ideas van calando en su memoria y los pequeños comprenden que hay un orden social jerárquico al que deben respetar y someterse:

El cura, el secretario y la Guardia Civil eran los jefes (Modesto, e. 1).

Al alcalde, al cura, al maestro y a la Guardia Civil les teníamos miedo y respeto (Felisa, e. 1).

El alcalde y el secretario son otras de las figuras que despiertan el interés infantil por su enorme poder local.

Mi padre, una vez, le dio la camisa azul el alcalde, para que fuera al Valle de los Caídos con él, cuando lo inauguraron (...). Le invitó para que fuera a verlo y tuvo que ir con la camisa azul (Felisa, e. 4). 
El secretario era el que más mandaba de todos (...). Era un señor muy inteligente, con su carrera, un hombre muy listo (...). Manejaba casi todos los asuntos del pueblo (Modesto, e. 1).

Entre los distintos poderes locales, el sacerdote ocupará un lugar destacado en la memoria de los protagonistas. En los núcleos rurales, la influencia y el control que esta figura ejerce sobre la infancia merece una atención especial en el análisis de datos. La presencia del párroco no solo puede apreciarse dentro del aula, sino también en el espacio comunitario.

Me acuerdo que pasábamos una vez por casa del cura, para ir a jugar detrás de la iglesia, y salió de casa y me llamó. Yo decía-iDios mío!, iqué me hará este hombre!-. Y dice -espera un momento- y yo asustadita. Me dice -que has hecho una cosa muy bien hecha y te la voy a decir. Has pasado por delante de la iglesia y te has santiguado-. Me fui yo a jugar más contenta... iMenudo miedo!, es que te metía un capón, por menos de nada. Él tenía derecho a hacer con los niños lo que le diera la gana (Felisa, e. 1).

La obligada asistencia de los menores a la iglesia favorece un contacto prolongado con la figura del sacerdote, posibilitando que este se convierta en un agente educativo de primer orden para la infancia. Los encuentros entre el párroco y los escolares son utilizados para inculcar a los pequeños la disciplina, la obediencia y el hábito de obrar bien (Sánchez, 2004, p. 240).

Nos pegaba y nos castigaba cuando le venía en gana... Anda que, a mí, cuantísimas veces me ha sacado a patadas de debajo del coro, donde daba la doctrina... ¡A mí y a muchos más! Nos sacaba a patadas en el culo... ¡Qué daño nos hacía! Me acuerdo que nos hacíamos pis hasta en los pantalones y todo (Modesto, e. 1).

Era fundamental que los escolares cuidaran las normas de «buena educación» hacia este poder local, que acataran su poder y respetaran su presencia.

Íbamos a besarle la mano... "buenos días tenga usted», le decíamos, y algún capón siempre nos ganábamos (Gloria, e. 2).

Estaba tan arraigada, entre la conciencia infantil, la importancia del sacerdote en la sociedad, que su figura era considerada inmortal para los pequeños.

Pensaba que, los curas (...) no se morían nunca. Claro, como el cura estaba al tanto de los enfermos, de la iglesia y... de todo, pues yo pensaba que ese hombre no se podía morir (Gloria, e. 2) 


\section{Cultura, fiestas populares y folclore}

Desde el inicio de la dictadura, las élites que sustentaban el nuevo Gobierno utilizaron la cultura popular en su propio beneficio. El folclore y la tradición se convirtieron en elementos legitimadores del franquismo y favorecieron la imposición de normas y controles entre la población (Criado, 2017). La religión ocupará un papel cardinal en las fiestas y actos folclóricos.

Una de las fiestas más importantes era la del Soto. Lo que más importaba aquí en esta fiesta eran las rogativas que se hacían a la Virgen, porque no llovía, y, entonces, se sacaba a la Virgen de procesión y se decía un cantar que decía así «¿Quién es aquella señora, que viene por los Linares? Es la Virgen del Soto, que viene regando los panes (Modesto, e. 5).

A través del folclore regional se presencia la relación entre religión y cultura; así como las diferencias entre sexos que se presentan a nivel social y la asunción de ciertos estereotipos masculinos y femeninos.

Se hacían bailes. Se bailaba la jota y se hacían paloteos... Los mozos del pueblo paloteaban en dos grupos - por un lado, solteros y, por otro, casados- (...). El paloteo representaba una tradición regional en honor a los santos (Felisa, e. 2).

El hombre es el principal protagonista en estos festejos locales. La mujer asume, de nuevo, un papel invisible en el ámbito público, como se constata a través de los narratorios. Las relaciones entre la Iglesia, la cultura y el sexo permiten el control de la moral femenina y sus comportamientos públicos (Manrique, 2014).

«San Blas» era el día tres de febrero... En el pueblo, había la tradición de correr las naranjas. Me acuerdo que se hacía en las eras y se hacía de la siguiente forma: se cogía una cuerda y se llenaba de naranjas, entonces, había dos personas a cada lado de la cuerda, agarrándola... Bueno, pues se ponían los mozos del pueblo a caballo y se ponían a correr con el caballo. Cuando llegabas a la cuerda, los hombres la levantaban y tenías que coger la naranja....Era muy difícil (Modesto, e. 6).

Mientras, las mujeres se quedaban mirando y aplaudiendo al hombre que cogía las naranjas (Felisa, e. 4).

El análisis realizado en líneas anteriores demuestra que, en la España franquista, la violencia y la guerra continuaron tras la guerra a través de la transmisión de la identidad nacional (Cazorla, 2002). 


\section{CONSIDERACIONES FINALES}

No cabe duda de que, como sostiene Schmidt (2010), el acceso a la realidad social e histórica por medio de la historia oral privilegia una mirada subjetiva. Es inevitable, como sostiene esta autora, que a través de las entrevistas se muestre una versión de la historia marcada por la influencia de las experiencias vividas. Eso es, precisamente, lo que hemos encontrado en nuestra investigación: las vivencias de un proceso histórico en cuatro personas que se convierten en cohistoriadoras.

Las memorias de esas vivencias coinciden, en líneas generales, con rasgos apuntados por la historiografía académica. Así, en las palabras de las personas cohistoriadoras, hemos encontrado rasgos fundamentales del desarrollo del nacionalcatolicismo representado por el Régimen franquista surgido de la Guerra Civil.

En su discurso están el culto a las figuras señeras del régimen, Franco y el caído José Antonio, la pretendida misión crucial de España basada en el destino universal de la nación que se contrapone a la autarquía del estudio casi exclusivo de la historia y de la geografía de España, la imposición de valores tradicionales, la utilización del folclore como pretendida fuente de uniformización cultural, el predomino exclusivo de una visión de la familia con unos roles de género muy diferenciados, la casi omnímoda presencia de la religión católica, el discurso político unilateral e impuesto...

Todas estas cuestiones están presentes en los estudios de investigación que sirven de fundamento teórico a nuestro trabajo. Sin embargo, hemos constatado que las fuentes orales permiten desvelar aspectos de nuestro pasado que sería imposible conocer a través de otro tipo de fuentes. En efecto, podemos afirmar que elementos muy relevantes se han puesto de manifiesto en las entrevistas, tal y como ha mostrado su análisis. Hemos confirmado, entre otras cuestiones, el papel referencial de símbolos como los retratos del dictador o del fundador de la Falange o del crucifijo, hemos constatado el miedo y la atribución de poderes cuasi sobrenaturales de las figuras del sacerdote o del maestro o la maestra y las sobrecogedoras consecuencias del ejercicio de un poder arbitrario por parte de las mismas, la naturalización de los procesos de segregación de sexos y la inculcación de la discriminación de género mediante la educación y el empleo del tiempo libre o la vinculación entre la política franquista y las celebraciones religiosas.

La descripción de estas vivencias constituye la prueba de que, tal y como señalan Sánchez Blanco y Hernández Huerta (2013), la educación franquista, al término de la Guerra Civil, quedó en manos de la Falange y de la Iglesia Católica, de tal manera que la primera orientó la formación política, cívica y física y la segunda impulsó el adoctrinamiento religioso hasta conseguir una muy profunda catolización que impregnaba todos los aspectos de la vida. Esta doble orientación de la educación no muestra diferencias, sino que en las vivencias de nuestros y nuestras protagonistas aparece como un todo unificado y coherente que se desarrolla no solo en la 
escuela, sino en cualquier dimensión social de la vida, hasta marcar de una manera decisiva las trayectorias vitales de las personas entrevistadas.

\section{REFERENCIAS BIBLIOGRÁFICAS}

Abdulla Muhammed, T. (2012). La figura de la mujer en la obra de Carmen Martín Gaite. (Tesis doctoral inédita). Universidad Autónoma de Madrid, Madrid.

Alted Vigil, A. (1996). Las consecuencias de la Guerra Civil española en los niños de la República: de la dispersión al exilio. Espacio, Tiempo y Forma, 9, pp. 207-228.

Alted Vigil, A. (1999). Le retour en Espagne des enfants évacués pendant la guerre civile espagnole: la Délégation extraordinaire au repatriement des mineurs (1938-1954). En: AA. VV., Enfants de la guerre civile espagnole. Vécus et représentations de la génération née entre 1925 et 1940. Paris, L'Harmattan, 1999, pp. 47- 59.

Alted Vigil, A. (2003). Los niños de la Guerra Civil. Anales de Historia Contemporánea, 19, pp. 43-58.

Araújo Machado, D. de. (2003). La utopía en los manuales de la Escuela Primaria en las dictaduras ibéricas del siglo XX (el Franquismo y el Salazarismo). Historia de la Educación, 22-23, pp. 371-385.

Badanelli Rubio, A. M. (2005). Emociones e imágenes de la construcción de las identidades de género. En P. Dávila y L. M. Naya (Coords.), La infancia en la historia: espacios y representación. XII Coloquio de Historia de la Educación. (Tomo II, pp. 285- 293). Donostia: Eiren

Badanelli Rubio, A. M. (2008). Ser español en imágenes: la construcción de la identidad nacional. Historia de la Educación, 27, pp. 137-169.

Badanelli, A. y Mahamud, K. (2011). Peeking into the classroom of post Civil War Spain. Children's classroom work, routines and dymanics. En S. Braster, I. Grosvenor, y M. Pozo (Eds.), The black box of schooling (pp. 81-98). Bruselas: Peter Lang.

Barceló, J. y Montes, M. J. (2016). Como nacían los tarraconenses. Evolución del modelo de asistencia al parto en la Cataluña franquista. MUSAS, 1(2), pp. 3-19. 
Bedmar, M. y Montero, I. (2010). Visión histórico-educativa en la España del franquismo. Influencias y repercusiones a través de los testimonios de vida de nuestros mayores. Revista de Investigación Educativa, 28(1), pp. 141-156.

Bergès, K. (2012). La nacionalización del cuerpo femenino al servicio de la construcción de la identidad nacional en las culturas políticas falangistas y franquistas. Mélanges de la Casa de Velázquez, 42(2), pp. 91-103.

Boyd, C. (2000). Historia Patria. Política, historia e identidad nacional en España: 1875-1975. Barcelona: Pomares Corredor.

Box, Z. (2016). Paisaje y nacionalismo en el primer franquismo. Hispanic Research Journal: Iberian and Latin American Studies, 17(2), pp. 123-140.

Cabrera García, M. I. (2012). El pasado como condición: discurso artístico e identidad nacional durante el primer franquismo. En M. P. García, M. E. Almarcha y A. Hernández, Historia, restauración y reconstrucción monumental en la posguerra española (pp. 41-64). Madrid: Abada Editores.

Casanova Ruíz, J. (2014). República y guerra civil. En J. Fontana y R. Villares (Dirs.), Historia de España (Vol. 8). Barcelona: Crítica - Marcial Pons.

Casero, E. (2000). La España que bailó con Franco. Coros y Danzas de la Sección Femenina. Madrid: Nuevas Estructuras.

Cazorla, A. (2002). Sobre el primer franquismo y la extensión de su apoyo popular. Historia y Política, 8, pp. 303-319.

Cazorla Sánchez, A. (2007). Patria Mártir: los españoles, la nación y la guerra civil en el discurso ideológico del primer franquismo. En J. Moreno Luzón (Ed.), Construir España. Nacionalismo español y procesos de nacionalización. Madrid: Centro de estudios políticos y constitucionales.

Chamizo Vega, C. (2009). Proceso de profesionalización de la enfermería en el principado de Asturias. (Tesis doctoral inédita). Universidad de Alicante, Alicante.

Colomer Rubio, J. C. (2015). Culturas políticas del nacionalismo español: el caso de la ciudad de Valencia (1958-1979). Franquisme \& Transició, 3, pp. 157-172. 
Colmeiro, J. F. (2005). Memoria histórica e Identidad cultural. De la posguerra a la postmodernidad. Barcelona: Anthropos editorial.

Criado, A. A (2017). El folclore como instrumento político: los coros y danzas de la Sección Femenina. Revista Historia Autónoma, 10, pp. 183-196.

Cucó i Giner, J. (2016). De la utopía revolucionaria a l'activisme: el Moviment Comunista, Revolta i Cristina Piris. (Tesis doctoral inédita). Universitat de València, Valencia.

Dávila Balsera, P. y Naya Garmendia, L. M. (2015). La construcción de la identidad nacional a través de los cuadernos escolares en el franquismo en el País Vasco. RIDPHE, 1(1), pp. 7-21.

Domenech Jiménez, M. I. (2016). Las maestras de la guerra civil y el primer franquismo en la provincia de Alicante. (Tesis doctoral inédita). Universidad de Alicante, Alicante.

Durante Asensio, I. (2014). Retóricas de la nostalgia: imagen, propaganda e identidad: los reportajes y documentales del NO-DO en la Región Murcia. (Tesis inédita de doctorado). Universidad de Murcia, Murcia.

Escolano Benito, A. (2006). Historia llustrada de La Escuela en España: dos siglos de perspectiva histórica. Madrid: Fundación Germán Sánchez Ruipérez.

Escudero Andújar, F. (2007). Dictadura y oposición al franquismo en Murcia. De las cárceles de la posguerra a las primeras elecciones. Editora Regional: Universidad de Murcia.

Fernández Santander, C. (1990). El fútbol durante la Guerra Civil y el franquismo. Madrid: San Martín.

Ferrer Cavón, J. (2012). La instrumentalización política de la cultura durante el primer franquismo: la Universidad Internacional Menéndez Pelayo (UIMP) y el Festival Internacional de Santander (FIS), 1945-1957. (Tesis inédita de doctorado). Universidad de Cantabria. Santander. España.

Font i Agulló, J. (2004). «Nosotros no nos cuidábamos de la política». Fuentes orales y actitudes políticas en el franquismo. El ejemplo de una zona rural, 1939-1959. Historia Social, 49, pp. 49-66. 
Fraser, R. (1993). Historia oral, historia social. Historia social, 17, pp. 131-140.

Fuertes Muñoz, C. (2012). La nación vivida. Balance y propuestas para una historia social de la identidad nacional española bajo el franquismo. En I. Sanz Campos y F. Archilés, La nación de los españoles: Discursos y prácticas del nacionalismo español en la época (pp. 279-300). Valencia: Universidad de Valencia. España.

Fusi Aizpurúa, J. P. (2000). España. La evolución de la identidad nacional. Madrid: Temas de hoy.

Fusi Aizpurúa, J. P. (2003). La patria lejana. El nacionalismo en el siglo XX. Madrid: Taurus.

Garbayo Maeztu, M. (2016). Dar presencia al cuerpo: prácticas performáticas en el tardofranquismo. Anales del Instituto de Investigaciones estéticas, 108, pp. 123- 147.

García Sebastiani, M. A. (2016). América y el nacionalismo español: las fiestas del 12 de octubre, del franquismo a la democracia. Historia y política: Ideas, procesos y movimientos sociales, 35, pp. 71-94.

Geniola, A. (2011). Provincia y Región en la España Foral y Asimilada. Particularismo franquista, erudición elitista y regionalismo oficial - nacionalista: Euskal Herria y Països Catalans durante el franquismo (Apuntes de investigación). En A. Barrio, J. de los Hoyos y R. Saavedra. Nuevos horizontes del pasado. Culturas políticas, identidades y formas de representación. Actas del X Congreso de la Asociación de Historia Contemporánea (p. 1).

Gil Alonso, F. y García Soler, A. (2009). La mortalidad en la infancia durante la Guerra Civil. Impacto territorial a partir del Censo de 1940. Revista Española de Investigaciones Sociológicas, 127, pp. 55-91.

Giori, P. (2014). Castell, cardanes i toros: Les disputes culturals dels nacionalismos durant el franquisme. Segle $X X, 7$, pp. 13-32.

Gómez García, S. (2009). Ya es Navidad en Radio Nacional: un análisis de las emisiones navideñas durante el primer franquismo (1939-1962). Enlaces, 10.

Gómez García, C. (2015). La pelota vasca y el NO-DO: un símbolo vasquista del noticiario cinematográfico franquista. Sancho el sabio, 38, pp. 117-136. 
González Calleja, E. y Limón Nevado, F. (1988). La Hispanidad como instrumento de combate: raza e imperio en la prensa franquista durante la guerra civil española. Madrid: CSIC.

González Calleja, E. (2014). El Real Madrid, ¿`equipo de España»? Fútbol e identidades durante el franquismo. Política y sociedad, 51 (2), pp. 275-296.

González Sáez, J. M. (2013). Geografía eclesial y construcción de la identidad nacionalista: La reivindicación de la provincia eclesiástica vasca durante el tardofranquismo y la transición. Historia contemporánea 46, pp. 307-332.

Guichot Reina, V. (2009). La cultura escolar del franquismo a través de la historia oral. Cuestiones Pedagógicas, 20, pp. 215-245.

Gutiérrez Lanza, C. (2000). Proteccionismo y censura durante la etapa franquista: Cine nacional, cine traducido y control estatal. León: Universidad de León, Servicio de Publicaciones, 2000.

Hastings, A. (2000). La construcción de las nacionalidades. Etnicidad, religión y nacionalismo. Madrid: Cambridge University Press.

Hernández Huerta, J. L., Sánchez Blanco, L. y Pérez Miranda, I. (2009). Temas y perspectivas sobre educación. La infancia ayer y hoy. Foro de Educación, 11, pp. 271-273.

Iglesias Iglesias, I. (2010). (Re) construyendo la identidad musical española; el jazz y el discurso cultural del franquismo durante la Segunda Guerra Mundial. Historia Actual Online, 23, pp. 119-135.

Inarejos Muñoz, J. A. (2013). Nacionalismos e identidades en la enseñanza de la historia de España: avances y resistencia. Clío: History and History Teaching, 39.

Labanyi, J. (1999). Raza, género y denegación en el cine español del primer franquismo: el cine de misioneros y las películas folclóricas. Archivos de la Filmoteca, 32, pp. 22-43.

Lapeire, K. (2010). Los niños de la guerra. La vida en la zona republicana (19361939). Cahiers de civilisation espagnole contemporaine, 6. Recuperado de: <https://ccec.revues.org/3271>. 
Leite Méndez, A. (2011). Historias de vida de maestros y maestras. La interminable construcción de las identidades: vida personal, trabajo y desarrollo profesional. (Tesis doctoral inédita). Universidad de Málaga, Málaga.

Lemus Diejo, M. T de. (2013). Libertad religiosa, simbología y derecho comparado. (Tesis doctoral inédita). Universidad de Salamanca, Salamanca.

Lida, Clara E. (1997). Los modelos europeos frente al caso español en el siglo XIX. Historia Social, 27, pp. 3-21.

Mahamud Angulo, K. (2010). Labor docente y trabajo escolar bajo el nacionalcatolicismo franquista (1945-1959). En J. Meda, D. Montino y R. Sani (Eds.), School exercise books. A complex source for a history of the approach to schooling and education in the 19th and 20th centuries (pp. 747-767). Florencia: Edizioni Polistampa.

Manrique Arribas, J. C, Torrego Egido, L., López Pastor, V. M. y Monjas Aguado, R. (2009). Factores que determinaron una educación física y deportiva de género durante el franquismo. Apunts, 98, pp. 5-14.

Manrique Arribas, J. C. (2007). La familia como medio de inclusión de la mujer en la sociedad franquista. Hispania Nova, 7.

Manrique Arribas, J. C. (2014). Incidencia del ideal de mujer durante el franquismo en ele ámbito de la familia y la actividad física. Feminismo/s, 23, pp. 47-68.

Manrique Arribas, J. C. (2011). Juventud, deporte y falangismo: El Frente de Juventudes, la Sección Femenina y los deportes del «movimiento». En X. Pujadas, Atletas y ciudadanos: historia social del deporte en España (1870 2010) (pp. 233-272). Madrid: Alianza Editorial.

Manrique Arribas, J. C. (2014). Actividad física y juventud en el franquismo (19371961). Revista Internacional de Medicina y Ciencias de la Actividad Física y el Deporte, 14(55), pp. 427-449.

Martín Fraile, B., Ramos Ruiz, I., y Hernández Díaz, J. M. (2010). Las consignas políticoreligiosas durante la etapa franquista en los cuadernos de rotación: currículum oculto y explícito En J. Meda, D. Montino, \& R. Sani (Eds.), School exercise books. A complex source for a history of the approach to schooling and education in the 19th and 20th centuries (pp. 237-255). Florencia: Edizioni Polistampa. 
Menéndez-Navarro, A. y Medina Doménech, R. M. (2003). Ausencia y primor «Mujer», tecnologías médicas e identidad nacional en el discurso del NO-DO. En P. Amador y R. Ruiz (Eds.), X Coloquio Internacional de la AEIHM. Representación, construcción e interpretación de la imagen visual de las mujeres (pp. 395-403). Madrid: Instituto de Cultura y Tecnología «Miguel de Unamuno».

Melloni, A. y Peñamarín, C. (1980). El discurso político en la prensa madrileña del franquismo. Roma: Bulzoni.

Molina Aparicio, F. (2005). La disputada cronología de la nacionalidad: fuerismo, identidad vasca y nación en el siglo XIX. Historia contemporánea, 30, pp. 219246.

Mora Díez, J. E. (2015). Identidad nacional y folclore popular en el primer cine de Pedro Almodóvar. AACA Digital, 30.

Moreno Seco, M. (2017). Cruce e identidades: masculinidad, feminidad, religión, clase y juventud en la JOC de los años sesenta. Historia política: Ideas, procesos y movimientos sociales, 37, pp. 147-176.

Morillo-Velarde Pérez, R. (2015). With and Army and Navy, lengua e identidad nacional. La Albolafia, 5, pp. 133-148.

Muñoz Mendoza, J. (2012). La construcción política de la identidad española: ¿del nacionalcatolicismo al patriotismo democrático? Madrid. Centro de Investigaciones Sociológicas.

Navarro Ardov, L. (2016). La nación evitada: identidad nacional en España y discursos de élites de izquierda. (Tesis inédita de doctorado). Universidad Pablo de Olavide, Sevilla.

Navarro García, C. (1993). La educación y el Nacional-Catolicismo. Castilla-La Mancha: Universidad de Castilla-La Mancha.

Navarro Sandalinas, R. (1990). La Enseñanza Primaria durante el franquismo (19361975). Barcelona: PPU.

Núñez Seixas, X.M. (2006). La España regional en armas y el nacionalismo de guerra franquista (1936-1939). Ayer, 64, pp. 201-231. 
Ortega Oroz, E. (2014). Entre el yugo y la flecha. Identidad nacional y de género en la representación cinematográfica de la Sección Femenina (1937-1945). (Tesis inédita de doctorado). Universitat Rovira i Virgili, Tarragona. España.

Otaola González, P. (2015). Canción española e identidad nacional en la España franquista: Manolo Escobar. Dedica, 7, pp. 33-52.

Palacio Lis, I. y Ruiz Rodrigo, C. (1993). Infancia, pobreza y educación en el primer franquismo: Valencia 1939-1951. Valencia: Universidad de Valencia.

Pedrero, M. G. y Piñero, C. (2006). Tejiendo recuerdos de la España de ayer. Experiencias de postguerra en el régimen franquista. Madrid: Narcea.

Peñamarín, C. (2002). El humor gráfico del franquismo y la formación de un territorio translocal de identidad democrática. Cuadernos de Información y comunicación, 7, pp. 351-380.

Piñeiro Blanca, J. (2013). Instrumentalización política de la música desde el franquismo hasta la consolidación de la democracia en España. Revista del Centro de Estudios Históricos de Granada y su Reino, 25, pp. 237-262.

Pozo Andrés, M. M. (2012). El movimiento de la Escuela Nueva en la España franquista (España, 1936-1976): repudio, reconstrucción y recuerdo. Revista Brasileira de História da Educaçao, 12(30), pp. 15-44.

Pozo Andrés, M. M. (2013). La construcción y la destrucción de la nación cívica desde la escuela en la Segunda República. Hispania nova. Revista de Historia Contemporánea, 11, (s. p.).

Rabazas Romero, T. (2001). Modelos de mujer sugeridos a las maestras en el franquismo. Bordón, 53 (3), 423-442.

Ramos Zamora, S. (2007). Historias de vida de los maestros castellano - manchegos en el primer franquismo. Idea La Mancha, 4, pp. 304-311.

Ramón Gabriel, M. y García Álvarez, J. (2016). Fotografía, turismo e identidad nacional en el primer franquismo (1939-1959): Rafael Calleja y la Apología Turística de España. Cuadernos de Turismo, 38, pp. 389-414. 
Rina Simón, C. (2017). Fascismo, nacionalcatolicismo y religiosidad popular. Combates por la significación de la dictadura (1936-1940). Historia y política: Ideas, procesos y movimientos sociales, 37, pp. 241-266.

Ródena García, J. L. (2012). Identidad nacional en el franquismo; repercusión identitaria del triunfo de Bahamontes en el Tour de Francia de 1959. En J. M. Aldea Celada, P. Ortega Martínez, I. Pérez Miranda, y M. R de Soto García (Coords.) Historia, identidad y alteridad: Actas del III Congreso Interdisciplinar de Jóvenes Historiadores (pp. 525-548). Salamanca: Hergar Ediciones Antema.

Rodríguez López, S. (2008). Los secretos de la memoria. Guerra Civil, Franquismo y fuentes orales en Almería. Pasado y Memoria, 7, pp. 263-283.

Sánchez Blanco, L. y Hernández Huerta, J. L. (2012). La educación femenina en el sistema educativo español (1857-2007). El futuro del pasado, 3, pp. 255-281.

Sanchidrián Blanco, C. (2004, septiembre). La construcción de la identidad de las niñas en el primer franquismo. Imágenes escolares. Ponencia presentada al XIII Congreso Nacional y II Iberoamericano de Pedagogía. La educación en contextos multiculturales: diversidad e identidad, organizado por la Sociedad Española de Pedagogía, Valencia (España).

Sanchidrián Blanco, C. y Arias Gómez, B. (2013). La construcción de la identidad nacional española a través de los cuadernos escolares (1957-1959). Revista de Investigación Educativa, 31(1), pp. 257-274.

Sanz Simón, C. y Rabazas Romero, T. (2017). La identidad nacional en los manuales escolares durante la Segunda República Española. Bordón, 69(2), 131-146.

Schmidt, S. (2010). Miradas sobre la migración argentina en España: fuentes orales, periodísticas y cinematográficas. El futuro del pasado, 1, pp. 557-581.

Serrano de Haro, A. (1946). España es así (15.a Edición). Madrid: Escuela Española.

Somoza Rodríguez, M. (2005). De la inocencia a la violencia: La identidad masculina en los manuales escolares. En P. Dávila y L. Naya (Coords.), La infancia en la historia: espacios y representaciones (pp. 330-339). Donostia: Eiren.

Sonlleva Velasco, M. (2016). ¿Con qué jugamos si no hay juguetes?: la infancia y el juego en la posguerra española (1939-1951) desde el relato de vida. Lúdicamente, 5(9). 
Sonlleva Velasco, M. (2017). La escuela rural (1939-1951) y su contexto. Entrevista a una alumna segoviana. Cabás, 17, pp. 150-167.

Sonlleva Velasco, M. y Torrego Egido, L. M. (2014). La escuela primaria del primer franquismo desde las voces del alumnado segoviano: una iniciación en la investigación educativa. Tendencias pedagógicas, 24, pp. 285-306

Soriano Trachiner, M. J. (2011). Sobrevivir al Collell. La construcción del mito de Rafael Sánchez Mazas en el primer franquismo a través de la prensa nacional. En A. Barrio, J de Hoyos y R. Saavedra, Nuevos Horizontes del pasado. Culturas políticas, identidades y formas de representación: Actas del X Congreso de la Asociación de Historia Contemporánea (p. 14).

Souto Larios, L. C. (2015). Ficciones sobre la expropiación de menores en el régimen franquista y la apropiación de menores en la dictadura argentina: el exterminio ideológico y sus consecuencias en la narrativa actual. (Tesis doctoral inédita). Universitat de València, Valencia.

Storm, E. (2013). Una España más española. La influencia del turismo en la imagen nacional. En J. Moreno y X. M. Núñez (Eds.). Ser españoles. Imaginarios nacionalistas en el siglo XX (pp. 530-560). Barcelona: RBA.

Tejerizo García, C. (2012). Identidad nacional y arqueología en el primer franquismo: Julio Martínez Santa - Olalla y la arqueología de la época visigoda. En J. M. Aldea Celada, P. Ortega Martínez, I. Pérez Miranda y M. R de Soto García (Coords.) Historia, identidad y alteridad: Actas del III Congreso Interdisciplinar de Jóvenes Historiadores (pp. 479-502). Salamanca: Hergar Ediciones Antema.

Torre Echávarri, J. I. de la. (2002). El pasado y la identidad española, el caso de Numancia. Arqueoweb, 4(1). Recuperado de: <http://pendientedemigracion. ucm.es/info/arqueoweb/pdf/4-1/delatorre.pdf>.

Yela Fernández, O. R. (2013). Infancias vulneradas en las guerras civiles de España y Guatemala. Una revisión desde el cine. El futuro del pasado, 4, pp. 207- 226.

Zabaleta Imaz, I, Garmendia Larrañaga, J. y Murua Cartón, H. (2015). Movimiento popular y escuela en el franquismo: las ikastolas en Gipuzkoa. Historia de la Educación, 34, pp. 305-336. 
Página intencionadamente en blanco. 